\title{
AC 2012-3880: A COURSE SEQUENCE IN ENGINEERING DESIGN AND PROBLEM SOLVING
}

\author{
Dr. David T. Allen, University of Texas, Austin
}

David Allen is the Gertz Regents Professor of chemical engineering, and the Director of the Center for Energy and Environmental Resources, at the University of Texas at Austin. He is the author of six books and more than 200 papers in areas ranging from coal liquefaction and heavy oil chemistry to the chemistry of urban atmospheres. For the past decade, his work has focused primarily on urban air quality and the development of materials for environmental and engineering education. Allen was a Lead Investigator for the first and second Texas Air Quality studies, which involved hundreds of researchers drawn from around the world, and which have had a substantial impact on the direction of air quality policies in Texas. He has developed environmental educational materials for engineering curricula and for the University's core curriculum, as well as engineering education materials for high school students. The quality of his work has been recognized by the National Science Foundation (through the Presidential Young Investigator Award), the AT\&T Foundation (through an Industrial Ecology Fellowship), the American Institute of Chemical Engineers (through the Cecil Award for contributions to environmental engineering and through the Research Excellence Award of the Sustainable Engineering Forum), the Association of Environmental Engineering and Science Professors (through their Distinguished Lecturer Award), and the state of Texas (through the Governor's Environmental Excellence Award). He has won teaching awards at the University of Texas and UCLA. Allen received his B.S. degree in chemical engineering, with distinction, from Cornell University in 1979. His M.S. and Ph.D. degrees in chemical engineering were awarded by the California Institute of Technology in 1981 and 1983. He has held visiting faculty appointments at the California Institute of Technology, the University of California, Santa Barbara, and the Department of Energy.

\section{Dr. Richard H. Crawford, University of Texas, Austin}

Richard H. Crawford is a professor of mechanical engineering at the University of Texas, Austin, and is the Temple Foundation Endowed Faculty Fellow No. 3. He received his B.S.M.E. from Louisiana State University in 1982 and his M.S.M.E. in 1985 and Ph.D. in 1989, both from Purdue University. He joined the faculty of UT in Jan. 1990 and teaches mechanical engineering design and geometry modeling for design. Crawford's research interests span topics in computer-aided mechanical design and design theory and methodology, including research in computer representations to support conceptual design, design for manufacture and assembly, and design retrieval; developing computational representations and tools to support exploration of very complex engineering design spaces; research in solid freeform fabrication, including geometric processing, control, design tools, manufacturing applications; and design and development of energy harvesting systems. Crawford is co-founder of the DTEACh program, a Design Technology program for K-12, and is active on the faculty of the UTeachEngineering program that seeks to educate teachers of high school engineering.

\section{Dr. Leema Kuhn Berland, University of Texas, Austin}

Leema Berland is an Assistant Professor of science education at the University of Texas, Austin. She earned a Ph.D. in the learning sciences from Northwestern University in 2008 and was a Doctoral Fellow with the NSF-funded Center for Curriculum Materials in Science (2003-2008). Berland is broadly interested in facilitating and studying students as they engage in complex communication practices. She is currently focused on exploring the dynamics of how and why students are able (or unable) to productively communicate in engineering classrooms, in the context of UTeachEngineering high school classrooms.

\section{Dr. Karen A. High, Oklahoma State University \\ Dr. Anthony J. Petrosino Jr, University of Texas, Austin}

Anthony Petrosino is a Learning Scientist and an Associate Professor of science and mathematics education and the Elizabeth G. Gibb Endowed Fellow at the University of Texas, Austin. He received his Ph.D. at Vanderbilt University, where he was a member of the Cognition and Technology Group at Vanderbilt (CTGV) for five years. While doing his doctoral work, Petrosino was a NASA Space Grant Fellow funded through the Department of Mechanical Engineering. He was a seven-year member of the NSF-funded 
VaNTH ERC and a Principle Investigator of a Department of Education funded PT3 grant. His additional research interests include informal science learning, engineering education and the development of expertise. While at the University of Texas, Austin, he helped establish the UTeach Teacher Preparation Program. Petrosino taught secondary science for seven years and is a certified K-12 teacher of science. In addition, he was an Assistant Superintendent of Schools for two years and was also a secondary school administrator for three years. His articles have appeared in the Journal of Science Education and Technology, the Journal of the Learning Sciences, Mathematical Thinking and Learning, Educational Computing Research, and the American Educational Research Journal.

\section{Theresa A. Dobbs, UTeachEngineering and University of Texas, Austin}

Theresa Dobbs joined UTeachEngineering in March 2009 as Senior Program Coordinator, working with the Summer Institute and the Master's of Arts and Science in Engineering Education programs for inservice teachers. Prior to joining UTeachEngineering, Dobbs worked at the UT's Center for Lifelong Engineering Education (CLEE) within the Cockrell School of Engineering. In her role as Senior Program Manager, she was responsible for the implementation of 100+ short courses, conferences, and certificate programs, with program topics covering a variety of engineering disciplines. Before joining the University of Texas, Austin, Dobbs worked for the National Alliance for Insurance Education and Research as a Program Coordinator. In all, Dobbs has more than 15 years management and meeting planning experience. Her education includes a B.B.A. in marketing from Texas A\&M University.

\section{Ms. Cheryl Farmer, UTeachEngineering}

Cheryl Farmer is the founding Program Manager and Project Director of UTeachEngineering. Funded through a five-year, \$12.5 million Math and Science Partnership grant from the National Science Foundation, UTeachEngineering offers a well-designed, well-rounded, design-based high school engineering course that can be implemented at low cost in virtually any setting, as well as a variety of professional development programs for pre-service and in-service teachers who want to add engineering to their teaching portfolio. Prior to co-founding UTeachEngineering, Farmer spent several years managing programs for both K-12 and higher education. Before entering higher education, Farmer worked as a Project Manager in the environmental field. Her education includes graduate work in mathematics and business administration and a B.A. in mathematics and liberal arts, with highest honors, from The University of Texas, Austin.

\section{Jill A. Marshall, University of Texas}

Jill A. Marshall is Assistant Co-director of the UTeach secondary STEM teacher preparation program. 


\section{A Course Sequence in Engineering Design and Problem Solving for Pre-Service Teachers}

\section{Introduction}

Hundreds of thousands of pre-college students are now being introduced to engineering through engineering academies, through dedicated year-long engineering courses and through integration of engineering concepts into science and mathematics courses ${ }^{1}$. New K-12 science education standards, proposed by the National Research Council, urge even more widespread inclusion and integration of engineering into K-12 science education ${ }^{2}$. Teachers participating in these initiatives will need to be familiar with engineering as a profession, engineering methods and habits of mind, and the application of science and mathematics in engineering design and problem solving. Pre-service teachers, preparing to become the next generation of middle and high school Science, Technology, Engineering and Mathematics (STEM) educators, will need to have some background engineering.

Engineering courses for pre-service middle and high school engineering teachers should be developed by engineering faculty and colleges of engineering, in collaboration with colleges of education. These pre-service teacher courses should be distinct from pathways for engineering students because: the pre-service teachers will have only a limited exposure to engineering, in contrast to engineering students who will experience an entire curriculum; pre-service teachers should be exposed to the full range of engineering disciplines, in contrast to engineering students who prepare to enter an engineering specialization; pre-service teachers are preparing for a career in education rather than a career in engineering; and pre-service teachers who will become engineering educators will have a wide range of mathematics and science backgrounds.

Engineering faculty involved in the UTeachEngineering project at The University of Texas, with the support of a Math and Science Partnership (MSP) grant from the National Science Foundation (NSF), have developed a three-course engineering sequence for science and mathematics students preparing to become secondary STEM educators. Students participating in these classes are enrolled in a pre-service teacher preparation program at the University that combines an undergraduate major in mathematics or science with pedagogical courses offered by the College of Education. This is one possible path for preparing the next generation of precollege engineering educators. Described below are the course learning objectives; the structure, content and activities of the courses; and the experiences from the first offerings the courses.

\section{Learning Objectives}

The learning objectives for the three-course sequence align with the UTeachEngineering project's definition of core learning objectives for all secondary students and teachers of engineering. These are organized into three categories: engineering practice, engineering process, and engineering skills and habits of mind.

\section{Learning Objectives Area 1: Engineering Practice}

- Engineering's Societal Impacts - Students learn about engineering's societal impacts through exploration of past accomplishments (greatest achievements) ${ }^{3}$; 
current and future challenges (grand challenges) ${ }^{4}$; and the relationship between changing societal needs, growing scientific and technological knowledge, and evolving designs.

0 Greatest Engineering Achievements of the $20^{\text {th }}$ Century ${ }^{3}$ with an emphasis on how these have impacted societies and students' daily lives.

o Grand Challenges for Engineering ${ }^{4}$ with an emphasis on how these will benefit societies and meet particular needs, and how students might contribute if they pursue engineering.

o Innovation and design evolution with an emphasis on impacts of innovation on society (and vice versa).

- The Practice of Engineering - Students learn about a variety of engineering disciplines and careers, the multidisciplinary nature of practice, and the professional codes and standards to which engineers adhere.

o Engineering disciplines and careers with an emphasis on the multidisciplinary nature of the practice.

o Engineering ethics and codes of practice.

o Safety considerations with respect to the system, the engineer and the user.

o Engineering standards and regulations, including the role of government.

o Legal aspects including intellectual property, patents, and trademarks.

Learning Objectives Area 2: Engineering Process - The engineering design process is a multi-step, iterative process that engineers use to design a product for a specific customer need.

- Identify (Identify the Need)

- $\quad$ Describe (Describe the Need; Characterize and Analyze the System)

- Generate (Generate Concepts; Select a Concept)

- Embody (Embody the Concept; Test and Evaluate the Concept; Refine the Concept)

- Finalize (Finalize and Share the Design)

\section{Learning Objectives Area 3: Engineering Skills and Habits of Mind}

- Systems thinking - Systems thinking is not one thing but a set of habits or practices within a framework that is based on the belief that the component parts of a system can best be understood in the context of relationships with each other and with other systems, rather than in isolation. Emphasis is placed on a top-down perspective, the system environment, and critical interfaces.

o System context and top-down perspective

o System decomposition (system, subsystem, element, component)

o Functional models, including input/output

- System understanding and quantification - Students learn to characterize the system using quantitative techniques common in the practice of engineering. A deeper understanding of the system is enabled through data acquisition, analysis and representation.

o Research (background, context, benchmarking)

o Information gathering (constraints, requirements, customer needs)

o Data acquisition, analysis and representation to develop performance targets

o Using appropriate instrumentation and experimentation techniques 
- Creativity - Students learn to use common tools and techniques that engineers use to approach and solve problems and to manage projects.

o Design approaches (e.g., new design, redesign, reverse engineering)

o Techniques for concept generation and selection

- Verification - Engineers must verify that their selected concept satisfies the design constraints, requirements, and customer needs.

o Design embodiment (modeling, prototyping)

o Data acquisition, analysis and representation to verify performance

- Communication - Students learn the importance of good communication skills and the unique aspects of how engineers document and present design ideas and analytical results. Emphasis is placed on creating communication artifacts to ensure accurate interpretation by others (with an eye toward clarity, detail, precision of process, and completeness).

0 Engineering notebooks and configuration management

o Formal documentation (e.g., reports, presentations)

- Collaboration - Students learn the importance of working on a multidisciplinary team in the practice of engineering as well as understanding what type of team member they are. Emphasis is placed on engineering personality types, integrated product teams, and examples of successful engineering teams.

o Teamwork (e.g., types of teams, group dynamics, team composition)

- Common Engineering Tools and Techniques - Students learn to use common tools and techniques that engineers use to solve problems and to manage projects. Approach and application are based on the specific design challenge at hand.

o Project management techniques (e.g., system cost and schedule estimation)

o Risk analysis techniques (e.g., failure modes and effects analysis)

o Software and technology tools

o Understanding/application of domain-specific math/science knowledge

These objectives are applicable to preparing pre-service students either to teach dedicated, yearlong high school engineering courses or to integrate engineering concepts into existing science and mathematics courses.

\section{Structure, Content and Activities of the Three-Course Sequence}

The three-course sequence is organized around the learning objectives areas outlined above. The first course in the sequence is a general introduction to engineering, the societal challenges (Grand Challenges and Great Achievements) that engineers address ${ }^{3,4}$ and the engineering design process. The second and third courses apply the engineering design process to a variety of challenges, requiring different types of engineering, mathematical and scientific skills.

All three of the courses introduce engineering fundamentals and design methods through rigorous design challenges, and a group of course design principles were employed in creating the courses. These principles include: 
- Engineering is taught through the application of a standardized engineering design process in a series of engineering design challenges;

- Exposure to the design process begins on the first day of the first class and continues, with increasing rigor, throughout the three-course sequence;

- Mathematical and scientific content required to address design challenges is delivered on a just-in-time basis;

- Students work in teams to create solutions to multi-disciplinary design challenges that are framed in the context of addressing societal needs; and

- All challenges include well-defined individual and group deliverables that allow students to demonstrate their understanding.

The first course employs four design challenges while the second and third courses use just one or two design challenges, as is done in undergraduate engineering capstone design courses.

\section{$\underline{\text { The First Course }}$}

The first course in the sequence, Engineering Design Methods, employs the following four design challenges:

1. Students (preservice teachers) begin with an engagement activity in which they take a familiar object, such as a can opener or an emergency light source, and quickly attempt to generate ideas for improving the designs. For example, the challenge may involve generating ideas for enabling a person with limited strength or mobility to operate a human-powered flashlight. Through the process of formally documenting their ideas, students are introduced to the concept of an engineering notebook, which is used and evaluated throughout the course sequence.

2. In the second design challenge, the students are introduced to the scope of engineering and careers available to engineers by examining the greatest engineering achievements of the $20^{\text {th }}$ century ${ }^{3}$ and the engineering grand challenges of the $21^{\text {st }}$ century ${ }^{4}$, as defined by the National Academy of Engineering. Simultaneously, they are given their first full design challenge: working in teams, students use engineering and kinematic principles to design and fabricate a superstructure to fit on top of a dynamics cart that maximizes volume (carrying capacity) and minimizes drag. The challenge is presented in the context of designing a roomy vehicle that can be fuel efficient, which allows students to understand the impact of competing objectives in design. Students generate concepts in their engineering notebooks and then select a design to fabricate. They build and quantitatively test their designs, determining drag coefficients and using simple flow visualization systems to identify sources of drag. Based on this information, they refine their concept and construct an improved design. Through this process, students are introduced to key components of the engineering design process (Figure 1), including methods for quantitatively describing objectives (maximize volume while minimizing drag); generating and selecting concepts; testing, evaluating and refining the concepts; and selecting a final design. This unit ends with a reflection on the design process. 


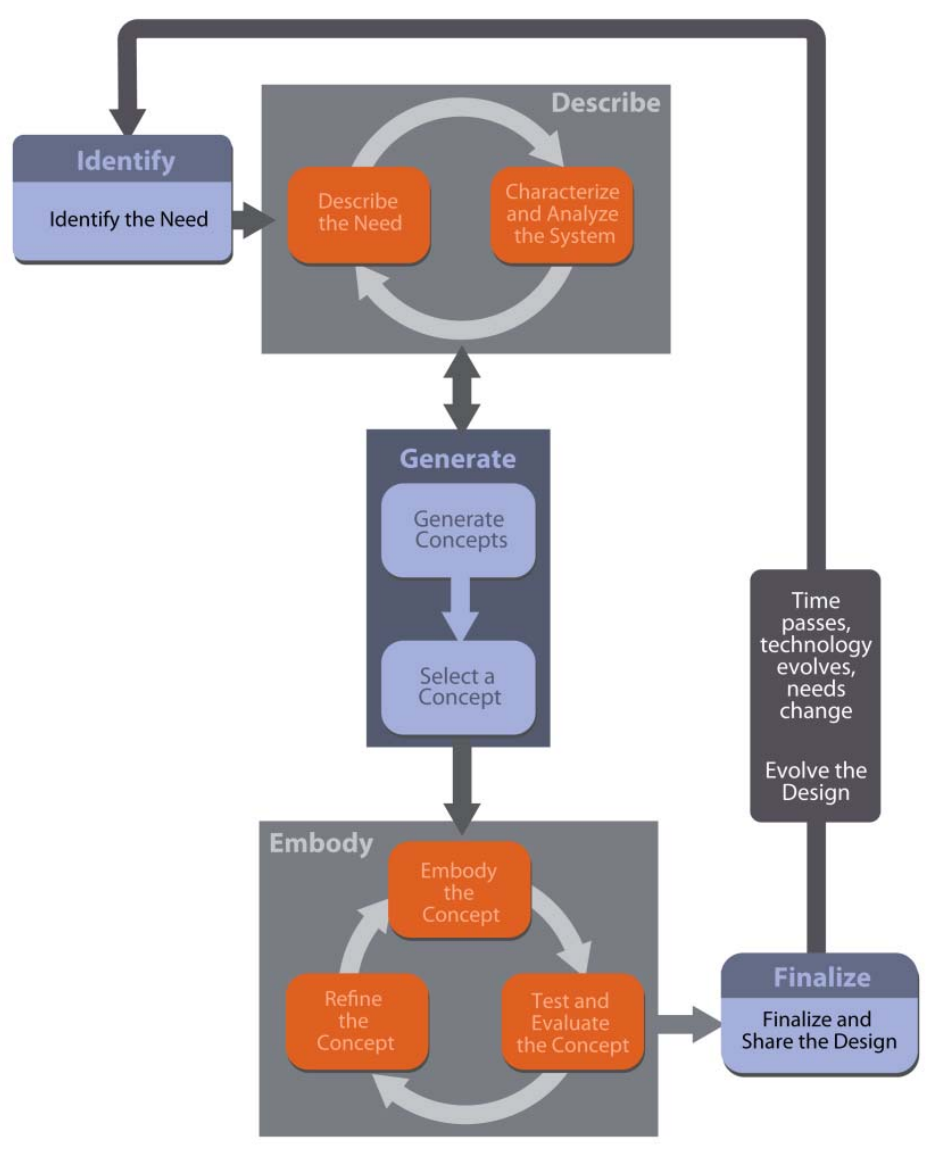

Figure 1. Engineering design cycle used as a framework for addressing design challenges in the courses

3. While the vehicle design challenge introduces students to the design process, it specifies the customer needs (maximize volume and minimize drag) and does not provide students with systematic methods for generating and selecting concepts. So, the third design challenge in the sequence introduces students to methods for defining customer needs and systematic methods for generating, evaluating and selecting design concepts. The focus of this challenge is reverse engineering and redesigning a widely used consumer product (for example, a hair drier). Working in pairs, the students are asked to conduct customer needs analysis through interviews and to map the results to quantifiable performance metrics. This emphasizes the notion that engineers must design solutions with customers in mind, but that the solutions must satisfy constraints. Teams sketch predicted internal structures of their products then disassemble the products and compare the results to their prediction. Functional models are created and the products are reassembled. Quantitative performance metrics that were identified earlier are measured to document the existing product's performance. The students then attempt redesign the product to improve one or more performance metrics. 
4. The vehicle design challenge and reverse engineering units allow students to discover and use the engineering design process illustrated in Figure 1. The fourth and final unit allows students to apply the design process to a student-generated design problem. Students commonly draw their ideas for this final challenge from their invention journal in which they have been recording thoughts about new or improved products in their daily activities. They develop preliminary plans for this project that can be embodied into a working prototype suitable for testing against specifications. Working in groups or individually, they meet with the instructor and make presentations to their peers.

\section{The Second and Third Courses}

Having completed the first course in the sequence, students have a broad overview of the types of challenges that engineers address, the process engineers use to design and the skills and habits of mind required to complete engineering challenges. The next courses in the sequence provide more in-depth instruction in particular engineering disciplines. Our intent is that a number of these courses will be offered to cover the spectrum of engineering disciplines. To date we have developed two of these courses: Engineering Energy Systems (chemical engineering focus) and Design of Machines and Systems (mechanical engineering focus). Both courses allow students to practice engineering processes, skills and habits of mind in the context of more open-ended challenges.

Engineering Energy Systems engages students in evaluating energy supplies, uses, energy system efficiencies, and potential future energy technologies. Examples of challenges undertaken in this course include:

- Wind and Water: Students design and integrate a wind turbine-power delivery system and a water pumping and storage system for a rural village with no access to the electrical grid, designing for the water needs of the village and the meteorological characteristics of the location.

- Emergency Power and Shelter: Students develop a system for emergency shelter and power suitable for use in a region that has experienced a hurricane that disrupts power delivery. Design constraints include the need to store the system when not in use, overall cost and the size of the system (number of people provided shelter and power delivery).

Design of Machines and Systems focuses on mechanical systems. Because many familiar devices and systems (e.g., appliances, toys, power tools, automobiles) are mechanical or electromechanical in nature, mechanical systems provide an approachable introduction to engineering for high school students. The mechanical systems course was designed to capitalize on this familiarity. In this course, students learn techniques for analyzing and designing machine components (e.g., linkages, cams, springs, gears). As each topic is studied, the students bring in examples they have encountered. These often become the focus of discussions of the topics. Additional examples are supplied by the faculty, implementing a rich active-learning approach to the subject area. Examples of challenges undertaken in this course include the following: 
- Reverse Engineering and Analysis of a Mechanical System: Students are given a mechanical or electromechanical system to analyze (e.g., radio-controlled car, electric can opener, electric mixer). In addition to customer needs analysis and functional modeling, students analyze major mechanical subsystems using techniques learned in class (e.g., linkage, drive train, energy storage, energy dissipation). Students must relate the analysis to important performance metrics.

\section{Experiences from the First Offerings}

The initial course offerings have been in the summer; this has allowed pre-service teachers to interact with in-service teachers who also take the courses to enhance their backgrounds in engineering. Typical classes have consisted of 15-20 students.

The most difficult challenges encountered in the initial offerings of the courses have been:

- Identifying appropriate design challenges: In many undergraduate engineering programs the goal of a capstone engineering design challenge is to present a highly realistic and technically sophisticated design challenge. In these courses, the goal is to preserve the realistic nature of the challenge while recognizing that the students will not have the same scientific, mathematical and engineering background as senior-level undergraduates majoring in engineering. Further, the challenges are intended to be representative of practices that could be successfully implemented in high school classrooms. Balancing realism with the ability to implement the challenge in a high school classroom was a continual challenge.

- Balancing depth of content with student preparation: This is similar to the issue above, particularly for the second and third courses in the sequence. These courses are modeled somewhat on existing upper-level courses for engineering undergraduate students, who typically have similar academic preparation in terms of completing prerequisites. In contrast, pre-service students come from a variety of different academic disciplines (although mostly natural sciences), and generally with no training in engineering perspectives. To address this, we must include background material necessary for the students to understand the main content topics. With this constraint, we have carefully chosen the topics themselves to be academically rigorous but transferable to the high school classroom.

- Evaluating student performance: Finding an appropriate balance between group and individual evaluations was a challenge. Many of the individual evaluations were based on entries in engineering notebooks, but most of the students enrolled in the course had little experience with the use of engineering notebooks. Incorporating an introduction to these practices into the course has evolved over time. 


\section{Conclusions and Next Steps}

The initial focus in developing these courses was to develop and refine the course content. Next steps will be to evaluate student outcomes. In engineering curricula, methods for evaluating course and program outcomes are defined by ABET. Student artifacts will be assembled and evaluated by a panel of engineering faculty. The faculty will develop rubrics for evaluating the artifacts, and the results of evaluations across multiple faculty panels will be assessed. In addition, analogous to the follow-up with engineering graduates performed for ABET engineering accreditation, the program will solicit feedback from graduates on the preparation provided to them by the program, and how it has impacted their teaching practices.

\section{Acknowledgement}

The UTeachEngineering program and the development of the courses described in this paper have been supported by the National Science Foundation through Math and Science Partnership grant DUE-0831811.

\section{Bibliographic Information}

1. National Research Council, Engineering in K-12 Education, National Academy Press, Washington, D.C., 2009.

2. National Research Council, A Framework for K-12 Science Education: Practices, Crosscutting Concepts, and Core Ideas, National Academy Press, Washington, D.C., 2011.

3. National Academy of Engineering, Greatest Engineering Achievements of the $20^{\text {th }}$ Century, available at: http://www.greatachievements.org, accessed January 2012.

4. National Academy of Engineering, Grand Challenges for Engineering, available at: http://www.engineeringchallenges.org , accessed January 2012.

5. ABET. (2012). Accreditation. Accessed at: http://www.abet.org/accreditation/ accessed March, 2012.

6. ABET. (2012). Criteria for Accrediting Engineering Programs, 2012-2013. Accessed at: http://www.abet.org/engineering-criteria-2012-2013/ accessed March, 2012. 